\title{
Seven Survival Senses: Evolutionary Training makes Discerning Differences more Natural than Spotting Similarities
}

\author{
Ravi Kashyap (ravi.kashyap@stern.nyu.edu) \\ City University of Hong Kong
}

March 11, 2021

Keywords: Involvement Quotient (IQ); Sense Organs; Evolution; Survive; Difference; Thrive; Similarity; Education Policy; Workforce Training

\begin{abstract}
Mathematical Subject Classification Codes: 92D15 Problems related to evolution; 92C55 Biomedical imaging and signal processing; 60G35 Signal detection and filtering; 97B10 Educational research and planning

JEL Codes: B15 Evolutionary; C73 Evolutionary Games; Z13 Economic Anthropology; A20 General Economic Education and Teaching of Economics

Edited Version: Kashyap, R. (2021). Seven Survival Senses: Evolutionary Training makes Discerning Differences more Natural than Spotting Similarities. World Futures, XX(X), XX-XX.
\end{abstract}

\section{Contents}

1 Abstract

2 Senses and Survival

3 Nonsense or Non-sense Organs

4 Sensing is More Than Just Seeing

1 The views and opinions expressed in this article, along with any mistakes, are mine alone and do not necessarily reflect the official policy or position of either of my affiliations or any other agency. The traceable seed for this paper was a talk by Sadhguru of Isha Foundation (Vasudev 2016) in which he mentioned that our sense organs are mainly for survival purposes. Mai Tran Anh Tuyet, Naresh Pandey and Ablina Serikova provided excellent assistance with conducting the experiments and other aspects of this paper. Dr. Yong Wang, Dr. Isabel Yan, Dr. Vikas Kakkar, Dr. Fred Kwan, Dr. William Case, Dr. Srikant Marakani, Dr. Qiang Zhang, Dr. Costel Andonie, Dr. Jeff Hong, Dr. Guangwu Liu, Dr. Humphrey Tung and Dr. Xu Han at the City University of Hong Kong; and numerous seminar participants provided advice and more importantly encouragement to explore and where possible apply cross disciplinary techniques. 
5 To Thrive or Senselessly Survive

6 Sleep and Sensing Symbolic Similarities

7 Evolution of Sense Organs $\quad 9$

8 Sensing Unseen Quirks called Quarks $\quad 10$

9 A Sensible Measure: The Involvement Quotient (IQ) 11

10 Stepping Forward Sensibly

11 End-notes (Some Sleeping Aids)

12 References (Some More Sleeping Aids)

13 Appendix: Details of Experiments $\quad 20$

13.1 Experiment Setup and Summary . . . . . . . . . . . . . . . . . . 20

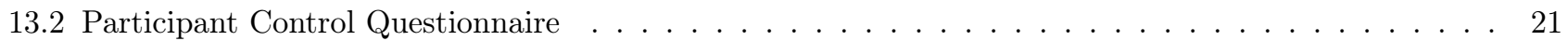

14 Figures $\quad[24$

\section{Abstract}

We discuss preliminary results from two experiments and put forth the notion that the development of sensory systems might be more geared towards discerning differences rather than for spotting similarities. We present the possibility that the necessity to spot differences might have evolved to ensure the survival of the organism, which suggests numerous other experiments to assess the response of participants to various stimuli. We consider our present state of affairs, wherein the need is to thrive and not merely survive, which requires us to spot similarities around us. We provide some suggestions on how this attribute can be developed, which includes mathematical education. We conclude with an alternate measure for intelligence, termed the Involvement Quotient (also, IQ), which gauges the level of involvement of the sense organs to whatever is happening around the individual.

\section{Senses and Survival}

Evolutionary trajectories that helped bring about the sense organs have been studied in great detail in various 
kinds of life forms (Payne 1971; Suthers 1978; Blaxter 1988; Kaas 1989; Endler 1993; Bennett \& Cuthill 1994; Gerhardt 1994; Janssen 2004; Endler, Westcott, Madden \& Robson 2005; Niven \& Laughlin 2008; Kaas 2008; Seehausen, ... \& Imai 2008; Seehausen, ... \& Brelsford 2014). We pinpoint a common theme among all these sensory developments, suggesting that they might be more geared towards discerning differences rather than for spotting similarities. The necessity to spot differences might have evolved to ensure survival of the organism. For the relationship between evolution and self-preservation or survival, see: (Doolittle \& Sapienza 1980; Dawkins 1976; 1982; De Catanzaro 1991; Brown, ... \& Biblarz 1999. End-note 1). Any change in the environment, coming across a different kind of food item or a different looking creature, could be a threat indicator. When things are identical to what we are used to, we deem that safer since the previous encounter did not prove to be fatal. Predators (also survivors) camouflage themselves to take advantage of this trait (Stevens \& Merilaita 2009).

We start with a discussion of what the sense organs actually do (Section 3). We provide preliminary results from two experiments in Section (4). The discussion suggests numerous other experiments to gauge the response of participants (animal or human) to visual (sight), auditory (sound), olfactory (smell), gustatory (taste), tactile (touch), vestibule (movement and balance) and proprioceptive (body awareness or where parts of our bodies are and how they are moving) stimuli. There is of course much discussion about other sense organs that we possess (Craig 2003; End-note 1). We venture onto other considerations regarding the sense organs in terms of our present need wherein we are not simply worried about mere survival (Section 5]. Our current necessity of having to go beyond survival requires us to spot similarities around us and we provide pointers on how this attribute can be developed (Sections 5:6). We ponder about what else might happen as we continue to evolve and the real difficulty with regards to spotting similarities (Sections 7, 8). We develop an alternate measure for intelligence also called the IQ, which is an abbreviation for the Involvement Quotient (Sections 9 10.

\section{Nonsense or Non-sense Organs}

The sense organs do an amazing job of collecting information from the world around us. But the actual sense that happens, of all this information that is gathered, is within the brain or the mind. An article by Bach-y-Rita, Tyler \& Kaczmarek (2003) titled "Seeing with the brain" sums it up better than any lengthy explanation we can provide. Though right now, it seems we don't know the difference between the mind and the brain (Churchland 1989; Oakley 2018). Hence much of what the sense organs collect is nonsense since the brain filters (for lack of a better word) through and picks up the relevant bits it deems important. This clearly tells us that the sense organs have been named incorrectly, they should be called nonsense organs. They can also be considered non-sense organs because they are not doing the actual sensing. They are simply collecting the stimuli, the sensing is happening somewhere else. 
An example to illustrate this is the following argument. There have been thousands and thousands of physicists or aspiring physicists in classrooms (and elsewhere) all around the globe, but we only have one Albert Einstein (Fölsing 1997). The point of this argument is that only a handful of physicists have shown us remarkable new insights into how the physical world works when compared to the number of candidates that are trying to glean the mysteries of the universe. All of them were learning similar things or being trained in similar techniques. But only some of them were able to make sense of what was happening around them or we have been able to make sense of only what some of them showed, did or said.

Another example is the well known story of Issac Newton and the apple. Newton discovered gravity, which has existed since time immemorial, only when an apple fell on his head (McKie \& De Beer 1951; Fara 1999; End-note 2). It is very likely that Newton had seen, tasted, smelled, touched, heard an apple (or other objects) fall before. But when it fell on his head, his brain (mind or whatever?) finally got the message. Though the truth behind this myth can be debated, the metaphor is relevant for us since we sometimes only notice things that hit us smack in the face. It is unfortunate that sometimes our sense organs fail to fully sense what is right in front of us and we fail to appreciate (sometimes even simply acknowledge or observe?) what is being handed to us on a platter or sent to us in a paper.

If we can categorize all (most?) human development into two broad categories, inventions and discoveries, we could cast all progress in terms of our sense organs. Inventions are new combinations of existing objects to enhance (or aid) our sense organs or our ability to perceive (and survive). Discoveries are existing phenomena that our sense organs have newly started to perceive. The subtle point behind this grouping of human ingenuity and its relation to our senses is that innovations and discoveries really mean something only if we experience it. Otherwise they are just words or symbols or stories of someone else until it happens to us. Lane \& Flagg (2010) consider discovery, invention and innovation as the three states of knowledge (also see, Marchetti 1980; Zahar 1983; Norman 2007). Simonton (1979) is a discussion of the occurrence of independent contributions by two or more scientists, which suggests that once we discover something for ourselves experientially, we have become scientists in our own right. Once anything happens to us, it is part of our story till then it is just his-story or history, which is less appealing to most people than their own narrative (Kashyap 2021b). Is it any wonder that Mysteries (My-Stories) are more appealing than Histories (His-Stories)? Montano-Rivas, McCasland, Dixon \& Bundy (2012) is an automated approach to theorem discovery and concept innovation, which shows that even machines have the potential to become scientists.

The real implication of this section is that, despite the seemingly obvious fact that we are living in the same world and we might be receiving the same (almost the same) stimuli from our surroundings, the universe we are creating in our head might be entirely different. This fact, (us living in the same world), becomes questionable and open to debate based on the arguments in the rest of this article. This could be succinctly described as we are all living in our own worlds. Frith (2013) captures this essence in the heading of their fifth chapter: "Our Perception 
of the World is a Fantasy that Coincides with Reality".

The central hypothesis of our paper considers the evolutionary reasons regarding why our senses fail to follow certain aspects of life all around us. We also provide suggestions on what experiments to conduct to understand this phenomenon that ignores what is right here (perhaps also known as ignorance), some ways to measure this tendency and ways to overcome it. Just because we do not see a connection does not mean that there is no connection. We need to try harder and be more open to acknowledging knowledge everywhere or we need to accept the possibility that something of value might have been brought to light about anything by anyone from anywhere.

\section{Sensing is More Than Just Seeing}

We have conduced the following two experiments numerous times across different participants. Figure (1) is a flow chart of the steps involved in the two experiments. Appendix (13) and in particular Points (1) 22 have more details. The first test (Appendix: Point 3) involves bringing up the picture shown in Figure (2) on a screen as we give participants instructions on various aspects of the experiment. At this point, we have not yet pointed out that what is on the screen is important for the experiment. Then we ask participants to describe what they see. People see the tree, the grass and many other things. Then we finally ask them if they saw the snake. In some cases we have shown words on the screen on top of the figure asking "Can you see the snake?". Some see it immediately after being given this clue, many see it a few moments later, many after a much longer time. No participant in all the tests done thus far has spotted the snake without being told that there was a snake there. Unless someone has seen the snake for themselves (we term this sensing the snake for lack of better words), there is no snake for them even if we give them all the information in the world.

Another, similar, experiment (Appendix: Point 4) we have conducted involves giving participants the following situation and asking them to describe what they see in Figure (3). The scenario is: "Imagine you are a wildlife photographer (Appendix: Point 5), walking about in the jungles of Cambodia. Your eyes glimpse something and you take a few photographs, one of which is shown on the screen. Why did you take this picture?" A small minority of the participants see the bird in the wildlife picture within a few seconds. But the initial reaction of many participants can be described as: peaceful, full of nature, I took the picture because I liked the scenery etc. But once they are prompted as to "what is the main mission of a wildlife photographer?", many participants see the bird soon after.

We will publish complete results for these experiments and various others in a separate paper. We emphasize that in the preliminary trials conducted thus far, we did not screen the participants for any deficiencies in eyesight including color blindness. In later rounds, we are collecting information regarding a number of control variables such as age, sex, education level, exam scores, nationality, etc. One other aspect to check for and control is for the 
amount of sleep participants had the night prior to this test (Appendix 13.2). This experiment illustrates that even though most of us receive the same information, the extent to which we make sense of it varies and is extremely subjective, depending on numerous factors, some innate and fundamental, such as eyesight and some proximate and easily rectifiable, such as lack of sleep. The results from this set of tests suggest that we can devise numerous experiments to measure all sorts of sensory faculties to confirm that differences are much easier to detect and it takes practice, patience and persistence to detect similarities.

\section{To Thrive or Senselessly Survive}

At present, the central aspect of our lives is not just to survive. Very few of us have to worry about whether we will have food to eat, whether we will eaten or if some conflict will end our lives. Though we do concern ourselves with whether to eat, and many times also what to eat and how much to eat. That we are able to spend countless hours on such endeavors as research and writing papers shows that we, as a civilization, are ready to thrive. We will thrive once we sense that situations and whatever we encounter have much in common with what we have encountered before, allowing us to utilize what we have learnt previously. This can be succinctly descried as being able to spot similarities.

For this to happen we have to work against the training of 4.5 billion years, which has developed to discern differences (End-note 3). Here, we emphasize that evolution is nothing but training, (or survival skills), that has kept certain genetic traits alive and passed them onto to later generations with minor successive alterations. Shubin (2008) suggests that evolution produced us from the first single celled organisms that appeared 3.5 billion years ago. But perhaps we are simply not able to sense what happened in the billion years before that when our planet formed and until the first living organisms were produced. We also need to think about whether the forces that created our universe around 13.8 billion years ago, give or take a few million years (End-note 4), were active in creating life as well before our planet formed and life, as we know it, took shape upon it. Now that the question of survival is no longer an issue, our intelligence or brain or mind, which was engaged in a very crucial aspect of life, is suddenly devoid of purpose (or a major purpose) bringing up numerous issues. One of which is that we imagine and create numerous problems for ourselves, which is nothing but our intelligence working against us due to a lack of intent or sufficient focus on essential activities (McKnight \& Kashdan 2009).

Thriving by spotting similarities requires skills or capabilities that the sense organs are not readily equipped to handle. This might need adjustments, or new developments altogether, to how we perceive the world around us. This perception can also be viewed as different levels of awareness regarding how we receive and process the information our sense organs collect. While evolution works at its own pace, there might be ways in which we can develop this aptitude to spot similarity. Being more attuned to distinguish alikeness might be a measure of how 
one can move beyond survival and the tests in Section (4), might be indicative of how this feature has developed in different individuals.

There are age old techniques that can help with increasing our abilities to appreciate alikeness. One such method which starts as early as kinder-garden is known as match the following. Figure (4) has two examples of this. The first one (Figure 4a is somewhat hard and the second one (Figure 4b is relatively easy and they are almost identical questions. A few moments of observation will tell us that the second one is in fact a clue to the first one. An alternative method involves merely judging if something is true or false. Mathematical variations of our question would involve checking if certain equations are true or false. Clearly these could also be rephrased as match the following, which would be a more direct test of spotting similarities. Another possibility is the, well known, spot the difference game, wherein differences come hidden or camouflaged among the similarities (Fukuba, etal 2009; End-note 5). The similarities or differences between spotting similarities or differences in terms of how our sensory organs and the brain are employed need to be studied further.

If match the following sounds easy, the next suggestion is even simpler. We simply need to be curios about everything. This is easier than it sounds. We don't have to be curios about everything at the same time. We just need to focus on whatever it is that is in front of us (or around us). This also simply means that we just have to fully engages our senses (perhaps all our senses) on whatever is around us. If being curios sounds unnatural, perhaps we could use a few more pointers (Section 6).

\section{$6 \quad$ Sleep and Sensing Symbolic Similarities}

As we wait for the perfect technique(s) to thrive, it is worth meditating upon what superior beings would do when faced with a complex situation such as the one we are in. It is said that the Universe is but the Brahma's (Creator's) dream (Ramamurthi 1995; Ghatage 2010). Research (Effort / Struggle) can help us understand this world; Sleep (Ease / Peace of Mind) can help us create our own world. (Wilkinson 1960; Ross 1965; Horne 1985; Tononi \& Cirelli 2006; Vassalli \& Dijk 2009; Barnes, Schaubroeck, Huth \& Ghumman 2011) are discussions about the functions of sleep and the adverse effects of sleep deprivation. It is worth noting that creating this alternate universe of dreams requires no noticeable use of the sense organs, indicating that the most powerful senses for perception are yet to be discovered and are not oriented to gathering signals from the external world.

Native to Australia (End-note 6), "Koalas spend about 4.7 hours eating, 4 minutes traveling, 4.8 hours resting while awake and 14.5 hours sleeping in a 24-hour period" (Nagy and Martin1985). The benefits of yoga on sleep quality are well documented (Khalsa 2004; Vera, ... \& Morell 2009; End-note 7). A lesson from close by and down under: "We need to Do Some Yoga and Sleep Like A Koala" (Figure 5). With that, we present a list of sleeping aids in Sections 111,12 . This does not necessarily mean that we need to sleep all the time. We need to be aware 
that the adequate amount of sleep varies across organisms and individuals. Getting sleep somewhere close to near optimal amounts could be crucial for being involved with our environment. This also brings up the question of what is yoga really? Yoga simply means being fully engaged, at this present moment, in whatever we are doing. This whatever could be: eating, drinking, laughing, smiling, talking, reading, experimenting, swimming and so on. This is nothing but making sure that all the senses that we control are right here and focused on whatever is around us. Now, of course, there are always too many things around us. But we can trust our brain or mind to zoom in on whatever we are supposed to focus on. As they say, do your best and someone will take care of the rest (Figure 6).

The sleep inducing effect of mathematics is observed in many older humans within classrooms across the world. This therapeutic effect is not observed in all of us, showing that there might be some of us made for math, or, just more ready to make sense of it. Kisner, Colby \& Borstad (2017) provide a definition of therapeutic exercises (End-note 8). Perhaps, babies also respond to Mathematics by falling asleep immediately, or, in certain other cases (not really extreme ones), by crying and displaying signs of being frightened (possibly, getting concerned, about which world and life they have ended up in?). More research is needed to explore this particular connection between mathematics in the womb and beyond. We could only find some research papers on babies and mathematics (Dehaene 2011; Skemp 1987). The one concern we have is that if such experiments start becoming popular, they might get classified under torture methods due to the possibility of leading to severe childhood trauma. This might attract the attention of human rights activists.

While the beauty and utility of mathematics are perhaps not to be debated, the training required to discern this loveliness is non-trivial. McAllister (2005) tries to uncover the sense of the term beauty as it is currently used by mathematicians. (Courant \& Robbins 1941; End-note 9) consider what mathematics really is? It might very well be the case that the dialect of mathematics we have adopted (with abstruse notation and omitted details, perhaps compounded by our evolutionary training to notice apparent incongruences), might not be that conducive to grasp meanings with. (Chinn 2013) is a comprehensive discussion of problems when dealing with math problems and consider how in mathematics another key communication factor is the use of symbols. This use of symbols introduces another layer, the need to relate symbols to vocabulary and to concepts. This suggests that mathematics might be about spotting similarities or truths, despite seemingly perplex means of expression, and is ideal training to sense the sameness in everything around us.

(Devlin 2000) argues that we might have an innate ability for mathematical thinking, even though the developments in higher math have been in the last 400 years or so, a time span which is as short as the flap of a butterfly's wings on an evolutionary scale. (Hoffert 2009; Whiteford 2009) are discussions about teaching mathematics, supposedly the universal language (Kashyap 2021), to students with deficiencies in the medium of instruction such as English. This also tells us that, as we try to consider all impediments to learning, we need to realize that the real obstacles might simply be to check whether information is being received in a comprehensible form (Lyon, Fletcher 
\& Barnes 2003; Wong 2011).

A deeper exploration of this topic will be pursued in other venues. But for now, it suffices for us to realize that a simple world can be made to appear complex easily. (Kashyap 2016) consider how a few simple deterministic rules can create a seemingly stochastic world. So instead of puzzling over the many elements of differences that we encounter, one of which is symbols we don't comprehend, our efforts might be well spent marveling the creations that cross our lives and spotting similarities among them. Let us not leave out those, so called, non-living things. Just because we don't see (sense?) a sign of life, does not mean that there is no life. This brings up the topic of Questions \& Answers, Q\&A. In this case, the question is: What is a Living creature? Biology, we suppose provides an answer, based on some Definitions and Assumptions, D\&A (Woese, Kandler \& Wheelis 1990). But if we change those D\&A, we might get different Q\&A, even telling us that D\&A (and Q\&A) might be in our very DNA, which are constantly being modified (Alberts 2017; End-note 10).

\section{$7 \quad$ Evolution of Sense Organs}

Most of accumulated scientific evidence points to the theory of evolution (Darwin 1859; Futuyma \& Kirkpatrick 2009; End-note 11). If the process of evolution produced human beings from so called other primitive life forms, this process must still be active in the descendants of other species from which we have evolved. This is of course the case, unless we argue and demonstrate that evolution has stopped in some of them. If this process is still active in other life forms it raises an important question: Are they evolving in ways we cannot yet completely distinguish and these developments simply do not make sense in our way of life? In addition, this process of evolution is still at work within human beings trying to alter our sense organs (and everything else) to the needs of today, with perhaps noticeable (by our current measurement techniques) alternations that will appear in the future. We discuss two instance of what might be a way forward for the evolution of sense organs.

A simple example of a possible evolutionary adaptation is the following: if a bomb were to explode in a crowded street, there would be chaos, with people running all around and even on top of each other. The following video (End-note 12) shows a school of fish dispersing as the film maker approaches them and as the fish sense the shadow of the film maker. Clearly, the approaching shadow is a sign of an impending threat. The fish react simultaneously in a remarkable way and scatter almost immediately without running into each other. We are continuing to run numerous experiments, as we endeavor to find explanations and other examples in later works, to sense (not just see?) if the fish are actually colliding and whether such a pattern of dispersion is the norm rather than the exception. Hemelrijk \& Hildenbrandt (2012) review model-based explanations for aspects of the shape and internal structure of groups of fish and of birds traveling undisturbed: that is, without predator threat. Reid, Hildenbrandt, Padding \& Hemelrijk (2012) acknowledge that experimentally studying the fluid dynamics of animal locomotion is difficult 
and time consuming, instead they suggest the use of model based studies.

Another instance of evolutionary adaptation is based on the use of electronic devices (phones, computers, etc.) in classrooms, while driving and elsewhere (Rockinson-Szapkiw, Courduff, Carter \& Bennett 2013; Baker, Lusk \& Neuhauser 2012; Chang, Aeschbach, Duffy \& Czeisler 2015; Strayer, Drews \& Crouch 2006). This topic is highly debated by policy makers and there seems to be no consensus on whether there needs to be a limit on the use of screens. Our senses have developed to help us survive by seeing far off things and developing the ability to hear, even faint sounds, from all around us. But do we really need these skills in the world today and what this world might become in the future. Perhaps we need to see and hear better only what is right in front of us, or at-least sense (concentrate more on) only close by stimuli. We need to be rest assured that evolution and its endless cycle of trials and errors will do the needful. Surely, policy needs to be formulated when electronic device usage is harmful to someone or their surroundings. But by forcing someone to do or not to do something when no clear negative consequence can be sensed, we are trying to intervene in the ways of evolution or with billions of years of wisdom with our near sighted compassion (End-note 13 .

\section{Sensing Unseen Quirks called Quarks}

We next pose the question: "How different could everything in this world be?", if everything is made of the same raw material, atoms, and just by creating different combinations of it. To create any universe similar to the one we physically dwell in, the only building block we need is an atom. With a certain level of understanding that overlooks other fundamental particles: electrons, quarks and whatnots (Harari 1979; Hooft 1996; Pohl, ... \& Giesen 2010). Given this similarity in our fundamental constitution and the marvelous differences we see both within our behavior and around us, we need to marvel at the amazing diversity that nature, or whoever or whatever, has created using just different combinations of the same basic building blocks. Life would be quite mundane without this variation. Variety is not just the spice of life, variety is life.

All information in the vastness of the universe, can be represented using just two symbols 0 and 1 . This includes knowledge and wisdom, without getting into the specifics of the corresponding definitions and assumptions, or D\&A, regarding how they might differ (Kashyap 2017). Shannon (1956) showed that two symbols were sufficient to duplicate a Turing Machine, the model for a general computer so long as enough states were used or vice versa (Turing 1937; Woods \& Neary 2009; End-note 15). The universes that we are creating, the so called virtual worlds using computers and related technologies are built with just two basic components, zero and one, will someday perhaps rival our own universe in complexity (Castronova 2008; Wolf 2014). And hence these virtual worlds are a complication compared to our physical world until we sense that zero and one might be similar or even identical in some sense. 
As we attempt to probe into the minutest depths of the world around us and to create artificial worlds that might surpass our so called real world, Mother Nature might take a cue and benevolently gift us new ways of perception to succeed in those efforts. If we really want something to happen, rest assured, evolution will develop new senses to make it a reality, sooner or later.

\section{A Sensible Measure: The Involvement Quotient (IQ)}

With billions and billions of years of training or preparation (a.k.a, evolution), any individual or organism is highly likely to excel at whatever it is supposed to do. Our current desire, almost an obsession, to measure everything including our intelligence would be better served if we realize that there is intelligence (even though in many cases it cannot be easily sensed) in everyone and everything that has undergone countless trials, errors and improvements. If every creature is capable of intelligence perhaps what differentiates individuals in tests is how involved they are in whatever they are doing. If someone is not fully engaged in whatever they are doing their intelligence, which has helped them successfully navigate numerous dangers, has not had a chance to be utilized fully. Hence any measure of IQ (Intelligence Quotient) is bound to be erroneous.

Also, if our body weights can change often, (and even our heights, but more gradually, perhaps?), our IQ, must be changing even more frequently. This is because our current measure of IQ depends on the brain, which is changing itself much more often than our weights (Doidge 2007). Hence, we must have very different IQ levels at different times. And if we can lose or gain weight, can we not easily do the same with our IQ levels as well? Weinberg (1989); Bartholomew (2004) describe the status of controversies regarding the definition of intelligence, whether intelligence exists and, if it does, whether it can be measured, and the relative roles of genes versus environments in the development of individual differences in intelligence.

The above discussion suggests that we are better of first testing how involved a person is in whatever they are doing. Checking this would mean gauging how well the sense organs are engaged in any task being attempted and what is the level of consciousness within the individual to the environment in which all this is happening. The series of tests for the sense organs, that our paper brings up, to distinguish similarities can serve as the foundation to assess the level of awareness towards the surroundings. We term this the Involvement Quotient (also, IQ).

\section{Stepping Forward Sensibly}

Our findings highlight that it is extremely hard to measure the actual level of intelligence within any organism. Perhaps, with our present perception of intelligence and prevailing tools to enhance our senses, we can never fully do this. The next best thing we can do is gauge the level of involvement or check how engaged the individual is with 
the surroundings and how much of their sense faculties are being utilized. Clearly, this suggests that we need to seriously rethink the current approach to measuring intelligence (IQ: Intelligence Quotient) and either completely substitute it or at-least complement those efforts with assessing involvement (IQ: Involvement Quotient). The other disclosure regarding the difficulty most of us seem to encounter while spotting similarities suggests that a valid path ahead would involve developing this attribute through training programs aimed at enhancing the engagement of our senses. Such training will facilitate better perception of alikeness. That these discoveries have numerous policy implications for education, workforce training and for the design of a society with greater well-being is a sensible summary of this discussion.

\section{End-notes (Some Sleeping Aids)}

1. A sense is a physiological capacity of organisms that provides data for perception. Senses of Living Organisms, Wikipedia Link

2. Squirreled away in the archives of London's Royal Society is a manuscript containing the truth, or perhaps the closest to one, about the apple. It is the manuscript for what would become a biography of Newton entitled Memoirs of Sir Isaac Newton's Life written by William Stukeley, an archaeologist and one of Newton's first biographers, and published in 1752 (Stukeley 1936). Newton told the apple story to Stukeley, who relayed it as such: "After dinner, the weather being warm, we went into the garden and drank tea, under the shade of some apple trees... he told me, he was just in the same situation, as when formerly, the notion of gravitation came into his mind. It was occasion'd by the fall of an apple, as he sat in contemplative mood. Why should that apple always descend perpendicularly to the ground, thought he to himself...". Newton Gravity Apple, Link

3. The age of Earth is estimated to be $4.54 \pm 0.05$ billion years $\left(4.54 \times 10^{9}\right.$ years $\left.\pm 1 \%\right)$. Age of Earth, Wikipedia Link

4. The age of the universe is the time elapsed since the Big Bang of around 13.8 billion years. Age of The Universe, Wikipedia Link

5. Spot the difference is a type of puzzle where players must find a set number of differences between two otherwise similar images. Spot the Difference, Wikipedia Link

6. The term Down Under is a colloquialism which is variously construed to refer to Australia and New Zealand. Australia or Down Under, Wikipedia Link 
7. Yoga is a group of physical, mental, and spiritual practices which originated in ancient India. Yoga, Wikipedia Link

8. Therapeutic effect refers to the response(s) after a treatment of any kind, the results of which are judged to be useful or favorable. Therapeutic Effect, Wikipedia Link

9. Mathematics (from Greek máthēma, "knowledge, study, learning") is the use of patterns to formulate new conjectures. Mathematicians resolve the truth or falsity of such by mathematical proof. When mathematical structures are good models of real phenomena, then mathematical reasoning can provide insight or predictions about nature. Mathematics, Wikipedia Link

10. Deoxyribonucleic acid (DNA) is a molecule composed of two chains (made of nucleotides) that coil around each other to form a double helix carrying the genetic instructions used in the growth, development, functioning and reproduction of all known living organisms and many viruses. DNA, Wikipedia Link

11. Evolution is change in the heritable characteristics of biological populations over successive generations. These characteristics are the expressions of genes that are passed on from parent to offspring during reproduction. Evolution, Wikipedia Link

12. A higher quality video which clearly shows the dispersion of the fish is available upon request. The YouTube version of this video is 10 times smaller in size than the original video. This also shows that a lot of sense is lost in translation, storage and transmission. Sensible Dispersion, Video Link

13. One reason, why such unwanted outcomes creep up is because we live in a world that requires around 2000 IQ points to consistently make correct decisions; but the smartest of us has only a fraction of that: (Ismail 2014; Kashyap 2021c; End-note 14). Hence, we need to rise above the urge to ridicule the seemingly obvious blunders of others because, without those marvelous mistakes, the path ahead will not become clearer for us.

14. Nassim Taleb and Daniel Kahneman discuss Trial and Error / IQ Points, among other things, at the New York Public Library on Feb 5, 2013. As Taleb explains, “... it is trial with small errors that leads to progress .... That being said, if there are big errors that might incapacitate the person trying the trial from further trials; as long as someone else has observed the attempts with huge errors, the rest of society benefits from it; assuming, of course, that the big blow up has left a non-trivial portion of society intact, or at-least not too shaken up. This concept is also an illustration of learning from the lessons history holds for us. (Ismail 2014) mentions the following quote from Taleb, "Knowledge gives you a little bit of an edge, but tinkering (trial and error) is the equivalent of 1,000 IQ points. It is tinkering that allowed the industrial revolution". This means that to match trial and error we need 1000 IQ points. But trial and error could still give the wrong 
outcomes. So in (End-note 13) we make the assumption that we need 2000 IQ points to consistently make the right decisions.

15. A Turing machine is a mathematical model of computation that defines an abstract machine, which manipulates symbols on a strip of tape according to a table of rules. Turing Machine, Wikipedia Link

\section{References (Some More Sleeping Aids)}

1. Alberts, B. (2017). Molecular biology of the cell. Garland science.

2. Bach-y-Rita, P., Tyler, M. E., \& Kaczmarek, K. A. (2003). Seeing with the brain. International journal of human-computer interaction, 15(2), 285-295.

3. Baker, W. M., Lusk, E. J., \& Neuhauser, K. L. (2012). On the use of cell phones and other electronic devices in the classroom: Evidence from a survey of faculty and students. Journal of Education for Business, 87(5), 275-289.

4. Barnes, C. M., Schaubroeck, J., Huth, M., \& Ghumman, S. (2011). Lack of sleep and unethical conduct. Organizational Behavior and Human Decision Processes, 115(2), 169-180.

5. Bartholomew, D. J. (2004). Measuring intelligence: Facts and fallacies. Cambridge University Press.

6. Bennett, A. T., \& Cuthill, I. C. (1994). Ultraviolet vision in birds: what is its function?. Vision research, $34(11), 1471-1478$.

7. Blaxter, J. H. (1988). Sensory performance, behavior, and ecology of fish. In Sensory biology of aquatic animals (pp. 203-232). Springer, New York, NY.

8. Bommer, M., Gratto, C., Gravander, J., \& Tuttle, M. (1987). A behavioral model of ethical and unethical decision making. Journal of business ethics, 6(4), 265-280.

9. Brown, B. B., Clasen, D. R., \& Eicher, S. A. (1986). Perceptions of peer pressure, peer conformity dispositions, and self-reported behavior among adolescents. Developmental psychology, 22(4), 521.

10. Brown, R. M., Dahlen, E., Mills, C., Rick, J., \& Biblarz, A. (1999). Evaluation of an evolutionary model of self-preservation and self-destruction. Suicide and Life-Threatening Behavior, 29(1), 58-71.

11. Castronova, E. (2008). Exodus to the virtual world: How online fun is changing reality. Palgrave Macmillan. 
12. Chang, A. M., Aeschbach, D., Duffy, J. F., \& Czeisler, C. A. (2015). Evening use of light-emitting eReaders negatively affects sleep, circadian timing, and next-morning alertness. Proceedings of the National Academy of Sciences, 112(4), 1232-1237.

13. Chinn, S. (2013). The trouble with maths: A practical guide to helping learners with numeracy difficulties. Routledge.

14. Churchland, P. S. (1989). Neurophilosophy: Toward a unified science of the mind-brain. MIT press.

15. Courant, R., \& Robbins, H. (1941). What is mathematics?. Oxford University Press.

16. Craig, A. D. (2003). Interoception: the sense of the physiological condition of the body. Current opinion in neurobiology, 13(4), 500-505.

17. Darwin, C. (1859). On the Origin of Species by Means of Natural Selection Or the Preservation of Favoured Races in the Struggle for Life. H. Milford; Oxford University Press.

18. Dawkins, R. (1976). The selfish gene. Oxford university press.

19. Dawkins, R. (1982). The extended phenotype: The long reach of the gene. Oxford University Press.

20. Dehaene, S. (2011). The number sense: How the mind creates mathematics. Oxford University Press.

21. De Catanzaro, D. (1991). Evolutionary limits to self-preservation. Ethology and Sociobiology, 12(1), 13-28.

22. Devlin, K. J. (2000). The math gene: How mathematical thinking evolved and why numbers are like gossip. New York: Basic Books.

23. Doidge, N. (2007). The brain that changes itself: Stories of personal triumph from the frontiers of brain science. Penguin.

24. Doolittle, W. F., \& Sapienza, C. (1980). Selfish genes, the phenotype paradigm and genome evolution. Nature, $284(5757), 601$.

25. Eisenberg, J. M. (1979). Sociologic influences on decision-making by clinicians. Annals of Internal Medicine, 90(6), 957-964.

26. Endler, J. A. (1993). Some general comments on the evolution and design of animal communication systems. Phil. Trans. R. Soc. Lond. B, 340(1292), 215-225.

27. Endler, J. A., Westcott, D. A., Madden, J. R., \& Robson, T. (2005). Animal visual systems and the evolution of color patterns: sensory processing illuminates signal evolution. Evolution, 59(8), 1795-1818. 
28. Fara, P. (1999). Catch a falling apple: Isaac Newton and myths of genius. Endeavour, 23(4), 167-170.

29. Fölsing, A. (1997). Albert Einstein: a biography. Viking. Chicago

30. Frith, C. (2013). Making up the mind: How the brain creates our mental world. John Wiley \& Sons.

31. Fukuba, E., Kitagaki, H., Wada, A., Uchida, K., Hara, S., Hayashi, T., ... \& Uchida, N. (2009). Brain activation during the spot the differences game. Magnetic Resonance in Medical Sciences, 8(1), 23-32.

32. Futuyma, D. J., \& Kirkpatrick, M. (2009). Evolution (Sinauer, Sunderland, MA).

33. Gardner, M., \& Steinberg, L. (2005). Peer influence on risk taking, risk preference, and risky decision making in adolescence and adulthood: an experimental study. Developmental psychology, 41(4), 625.

34. Gerhardt, H. C. (1994). The evolution of vocalization in frogs and toads. Annual Review of Ecology and Systematics, 25(1), 293-324.

35. Ghatage, S. (2010). Brahma's Dream. Anchor Canada, Penguin Random House, Manhattan, New York.

36. Harari, H. (1979). A schematic model of quarks and leptons. Physics Letters B, 86(1), 83-86.

37. Hemelrijk, C. K., \& Hildenbrandt, H. (2012). Schools of fish and flocks of birds: their shape and internal structure by self-organization. Interface focus, rsfs20120025.

38. Hoffert, S. B. (2009). Mathematics: The Universal Language?. Mathematics Teacher, 103(2), 130-139.

39. Hooft, G. T. (1996). In search of the ultimate building blocks. Cambridge University Press.

40. Horne, J. A. (1985). Sleep function, with particular reference to sleep deprivation. Annals of clinical research, 17(5), 199-208.

41. Ismail, S. (2014). Exponential Organizations: Why new organizations are ten times better, faster, and cheaper than yours (and what to do about it). Diversion Books.

42. Janssen, J. (2004). Lateral line sensory ecology. In The Senses of Fish (pp. 231-264). Springer, Dordrecht.

43. Kaas, J. H. (1989). The evolution of complex sensory systems in mammals. Journal of Experimental Biology, $146(1), 165-176$.

44. Kaas, J. H. (2008). The evolution of the complex sensory and motor systems of the human brain. Brain research bulletin, 75(2-4), 384-390.

45. Kashyap, R. (2016). Notes on Uncertainty, Unintended Consequences and Everything Else. Working Paper, Social Science Research Network: https://papers.ssrn.com/sol3/papers.cfm?abstract_id=2741040 
46. Kashyap, R. (2017). Microstructure under the Microscope: Tools to Survive and Thrive in The Age of (Too Much) Information. The Journal of Trading, 12(2), 5-27.

47. Kashyap, R. (2021). The Universal Language: Mathematics or Music? Journal for Multicultural Education, Forthcoming.

48. Kashyap, R. (2021b). Do Traders Become Rogues? or Do Rogues Become Traders? The Om of Jerome and The Karma of Kerviel... Arizona State University Corporate and Business Law Journal, 1(3), XX-XX, Forthcoming.

49. Kashyap, R. (2021c). Artificial Intelligence: A Child's Play. Technological Forecasting \& Social Change, Forthcoming.

50. Khalsa, S. B. S. (2004). Treatment of chronic insomnia with yoga: A preliminary study with sleep-wake diaries. Applied psychophysiology and biofeedback, 29(4), 269-278.

51. Kisner, C., Colby, L. A., \& Borstad, J. (2017). Therapeutic exercise: foundations and techniques. F.A. Davis Company.

52. Lane, J. P., \& Flagg, J. L. (2010). Translating three states of knowledge-discovery, invention, and innovation. Implementation Science, 5(1), 9.

53. Lyon, G. R., Fletcher, J. M., \& Barnes, M. C. (2003). Learning disabilities. In E. J. Mash \& R. A. Barkley (Eds.), Child psychopathology (p. 520-586). Guilford Press.

54. Marchetti, C. (1980). Society as a learning system: discovery, invention, and innovation cycles revisited. Technological forecasting and social change, 18(4), 267-282.

55. McAllister, J. W. (2005). Mathematical beauty and the evolution of the standards of mathematical proof. In M. Emmer (Ed.), The visual mind II (Vol. 2). Cambridge: MIT.

56. McKie, D., \& De Beer, G. R. (1951). Newton's apple. Notes and Records of the Royal society of London, $9(1), 46-54$.

57. McKnight, P. E., \& Kashdan, T. B. (2009). Purpose in life as a system that creates and sustains health and well-being: an integrative, testable theory. Review of General Psychology, 13(3), 242.

58. Montano-Rivas, O., McCasland, R., Dixon, L., \& Bundy, A. (2012). Scheme-based theorem discovery and concept invention. Expert Systems with Applications, 39(2), 1637-1646. 
59. Nagy, K. A., \& Martin, R. W. (1985). Field Metabolic Rate, Water Flux, Food Consumption and Time Budget of Koalas, Phascolarctos Cinereus (Marsupialia: Phascolarctidae) in Victoria. Australian Journal of Zoology, 33(5), 655-665.

60. Niven, J. E., \& Laughlin, S. B. (2008). Energy limitation as a selective pressure on the evolution of sensory systems. Journal of Experimental Biology, 211(11), 1792-1804.

61. Norman, A. L. (2007). Informational society: An economic theory of discovery, invention and innovation. Springer Science \& Business Media.

62. Oakley, D. A. (Ed.). (2018). Brain and mind. Routledge.

63. Payne, R. S. (1971). Acoustic location of prey by barn owls (Tyto alba). Journal of Experimental Biology, $54(3), 535-573$.

64. Podduwage, D. R., \& Ratnayake, P. (2020). Wildlife Photography over Nature Photography. The International Journal of Social Sciences and Humanities Invention, 9(9), 49-52.

65. Pohl, R., Antognini, A., Nez, F., Amaro, F. D., Biraben, F., Cardoso, J. M., ... \& Giesen, A. (2010). The size of the proton. Nature, 466(7303), 213.

66. Ramamurthi, B. (1995). The fourth state of consciousness: The Thuriya Avastha. Psychiatry and clinical neurosciences, 49(2), 107-110.

67. Reid, D. A., Hildenbrandt, H., Padding, J. T., \& Hemelrijk, C. K. (2012). Fluid dynamics of moving fish in a two-dimensional multiparticle collision dynamics model. Physical Review E, 85(2), 021901.

68. Rockinson-Szapkiw, A. J., Courduff, J., Carter, K., \& Bennett, D. (2013). Electronic versus traditional print textbooks: A comparison study on the influence of university students' learning. Computers \& Education, $63,259-266$.

69. Ross, J. J. (1965). Neurological findings after prolonged sleep deprivation. Archives of neurology, 12(4), 399-403.

70. Seehausen, O., Terai, Y., Magalhaes, I. S., Carleton, K. L., Mrosso, H. D., Miyagi, R., ... \& Imai, H. (2008). Speciation through sensory drive in cichlid fish. Nature, 455(7213), 620.

71. Seehausen, O., Butlin, R. K., Keller, I., Wagner, C. E., Boughman, J. W., Hohenlohe, P. A., ... \& Brelsford, A. (2014). Genomics and the origin of species. Nature Reviews Genetics, 15(3), 176.

72. Shannon, C. E. (1956). A universal Turing machine with two internal states. Automata studies, 34, 157-165. 
73. Shubin, N. (2008). Your inner fish: a journey into the 3.5-billion-year history of the human body. Vintage.

74. Simonton, D. (1979). Multiple discovery and invention: Zeitgeist, genius, or chance?. Journal of Personality and Social Psychology, 37(9), 1603-1616.

75. Skemp, R. R. (1987). The psychology of learning mathematics. Psychology Press.

76. Stevens, M., \& Merilaita, S. (2009). Animal camouflage: current issues and new perspectives. Philosophical Transactions of the Royal Society of London B: Biological Sciences, 364(1516), 423-427.

77. Strayer, D. L., Drews, F. A., \& Crouch, D. J. (2006). A comparison of the cell phone driver and the drunk driver. Human factors, 48(2), 381-391.

78. Stukeley, W. (1936). Memoirs of Sir Isaac Newton's Life. Taylor and Francis.

79. Suthers, R. A. (1978). Sensory ecology of birds. In Sensory Ecology (pp. 217-251). Springer, Boston, MA.

80. Tononi, G., \& Cirelli, C. (2006). Sleep function and synaptic homeostasis. Sleep medicine reviews, 10(1), 49-62.

81. Turing, A. M. (1937). On computable numbers, with an application to the Entscheidungsproblem. Proceedings of the London mathematical society, 2(1), 230-265.

82. Vassalli, A., \& Dijk, D. J. (2009). Sleep function: current questions and new approaches. European Journal of Neuroscience, 29(9), 1830-1841.

83. Vasudev, J. (2016). Inner Engineering: A Yogi's Guide to Joy. Spiegel \& Grau.

84. Venkatesh, V., Morris, M. G., \& Ackerman, P. L. (2000). A longitudinal field investigation of gender differences in individual technology adoption decision-making processes. Organizational behavior and human decision processes, 83(1), 33-60.

85. Vera, F. M., Manzaneque, J. M., Maldonado, E. F., Carranque, G. A., Rodriguez, F. M., Blanca, M. J., \& Morell, M. (2009). Subjective sleep quality and hormonal modulation in long-term yoga practitioners. Biological psychology, 81(3), 164-168.

86. Weinberg, R. A. (1989). Intelligence and IQ: Landmark issues and great debates. American Psycholo- gist, 44(2), 98.

87. Whiteford, T. (2009). Is Mathematics a Universal Language?. Teaching Children Mathematics, 16(5), 276283. 
88. Wilkinson, R. T. (1960). The effect of lack of sleep on visual watch-keeping. Quarterly Journal of Experimental Psychology, 12(1), 36-40.

89. Woese, C. R., Kandler, O., \& Wheelis, M. L. (1990). Towards a natural system of organisms: proposal for the domains Archaea, Bacteria, and Eucarya. Proceedings of the National Academy of Sciences, 87(12), 4576-4579.

90. Wolf, M. J. (2014). Building imaginary worlds: The theory and history of subcreation. Routledge.

91. Wong, B. (Ed.). (2011). Learning about learning disabilities. Elsevier.

92. Woods, D., \& Neary, T. (2009). The complexity of small universal Turing machines: A survey. Theoretical Computer Science, 410(4-5), 443-450.

93. Zahar, E. (1983). Logic of discovery or psychology of invention?. The British Journal for the Philosophy of Science, 34(3), 243-261.

\section{Appendix: Details of Experiments}

\subsection{Experiment Setup and Summary}

1. The group sizes ranged from 25 to 60 . We are performing more group experiments and also trying this on individuals after collecting information for a set of control questions (Appendix 13.2). For all the group experiments, all human and animal subjects were engaged in their natural environment, hence the only indication given that this was an experiment was in mentioning that this could be a topic of a research paper. Individual testing will explicitly make clear that this is an experiment and specific protocols for human and animal testing will be followed. If necessary, participant signature and email address or phone number will be collected as indication of their consent to voluntarily participate in this experiment. We also record the date, time, city and country regarding the conduct of the individual test. The data collection from the individual experiments will be subjected to numerous quantitative analysis techniques. The objective of the analysis would be establish the factors that indicate a higher degree of involvement of the individual with the surroundings and the activities they are performing. This will allow us to develop programs at all levels of education to ensure individuals can perform at the peak of their abilities. 
2. Picture one in the flowchart in Figure 1 refers to Figure 2. Picture two in the flowchart in Figure 1 refers to Figure 3

3. The response time to spot the snake varies from a couple of seconds to almost many minutes. When this experiment was conducted in groups and once someone has seen the snake and mentions it, some other members say that they see it too. If they are then questioned, where is the snake? They point to a wrong location in the picture. This tells us how we sometimes make decisions based on what we see others doing or saying, which we believe is correct, even though it has not come to us experientially or something that has resonated with our senses, perception and understanding. This effect can be broadly identified as having some overlaps with the many studies conducted under the label: Peer Pressure (Eisenberg 1979; Brown, Clasen \& Eicher 1986; Bommer, Gratto, Gravander \& Tuttle 1987; Venkatesh, Morris \& Ackerman 2000; Gardner \& Steinberg 2005).

4. A small minority of the participants see the bird in the wildlife picture within 5 seconds.

5. We use the definition of Wildlife Photography found at this link: Definition of Wildlife Photopgraphy, Link (also see, Podduwage \& Ratnayake 2020; Wildlife Photography, Wikipedia Link). The Photographic Society of America (PSA) which represents 6500 members and 470 camera clubs, the Fédération Internationale de l'Art Photographique (FIAP) which represents more than 85 national associations and The Royal Photographic Society (RPS) with over 11,000 UK and international members will all use the same definition for nature and wildlife categories for their respective competitions and exhibitions. The new definition will come in to effect from 1 January 2015.

\subsection{Participant Control Questionnaire}

It is optional for the participants to provide answers to these control questions (partial list).

1. How old are you?

2. Do you identify with any gender?

3. How many characters are there in your name?

4. What is your nationality? 
5. What is your education level?

6. Are you currently working full time?

7. Are you currently working part time?

8. If yes to 6 or 7 what is the nature of your work?

9. Are you currently studying full time?

10. Are you currently studying part time?

11. If yes to 9 or 10 , what are you studying?

12. How many languages do you speak?

13. How many languages can you read and write?

14. What is your mother tongue?

15. Which language are you most comfortable speaking?

16. Which language are you most comfortable reading and writing?

17. Which sports do you play?

18. How many times a week?

19. How long do you play each time in hours?

20. Do you go to the gym?

21. How many times a week?

22. How long do you go to the gym each time in hours?

23. How many countries have you traveled to?

24. How many hours of sleep do you get on average?

25. How many hours of sleep did you get yesterday?

26. Please provide any Exam Score [International English Language Testing System (IELTS), Graduate Management Admission Test (GMAT), Test of English for International Communication (TOEIC), Test of English as a Foreign Language (TOEFL), Other]. 
(a) Exam and Score are noted down.

27. Have you taken any course in mathematics or the latest math course you took?

28. If yes to 27, Was this during high school, undergraduate or graduate level?

29. If yes to 27, What was your grade in that mathematics course?

30. If yes to 27. What was the maximum possible grade for that math course?

31. If yes to 27. What was your overall GPA (Grade Point Average) for the program the above course was part of? If not completed, latest GPA.

32. If yes to 27. What is the maximum GPA possible for the program the above course was part of?

33. What was your major at the last institution or school you attended? Or, What is your major at the present institution or school you are attending: ${ }^{2}$

34. What was the name of the last university or school you attended? Or, What is the name of the present university or school you are attending?

35. How many hours do you spend on your phone everyday?

36. How many hours do you spend on your computer everyday?

37. How many hours of television do you watch everyday?

38. How many hours do you read a regular printed book everyday?

39. Do you have color blindness?

40. Do you wear contact lens or glasses?

41. If yes to 40 , What is the reason for wearing glasses or contact lens?

42. Have you had corrective eye surgery?

43. Do you have any other eye sight defects?

44. Have you ever been operated under the use of general anesthesia?

45. Do you like mathematics?

\footnotetext{
${ }^{2}$ Despite the similarity between this question and question 11 we wish to highlight that the answers could be different? There could be a difference between what we are studying and our majors! Also, for someone currently studying, the answer to this question could be the institution attended before attending this present one.
} 
46. What time of the day do you feel most energetic usually? (Morning, Afternoon, Evening or Night)

\section{Figures}

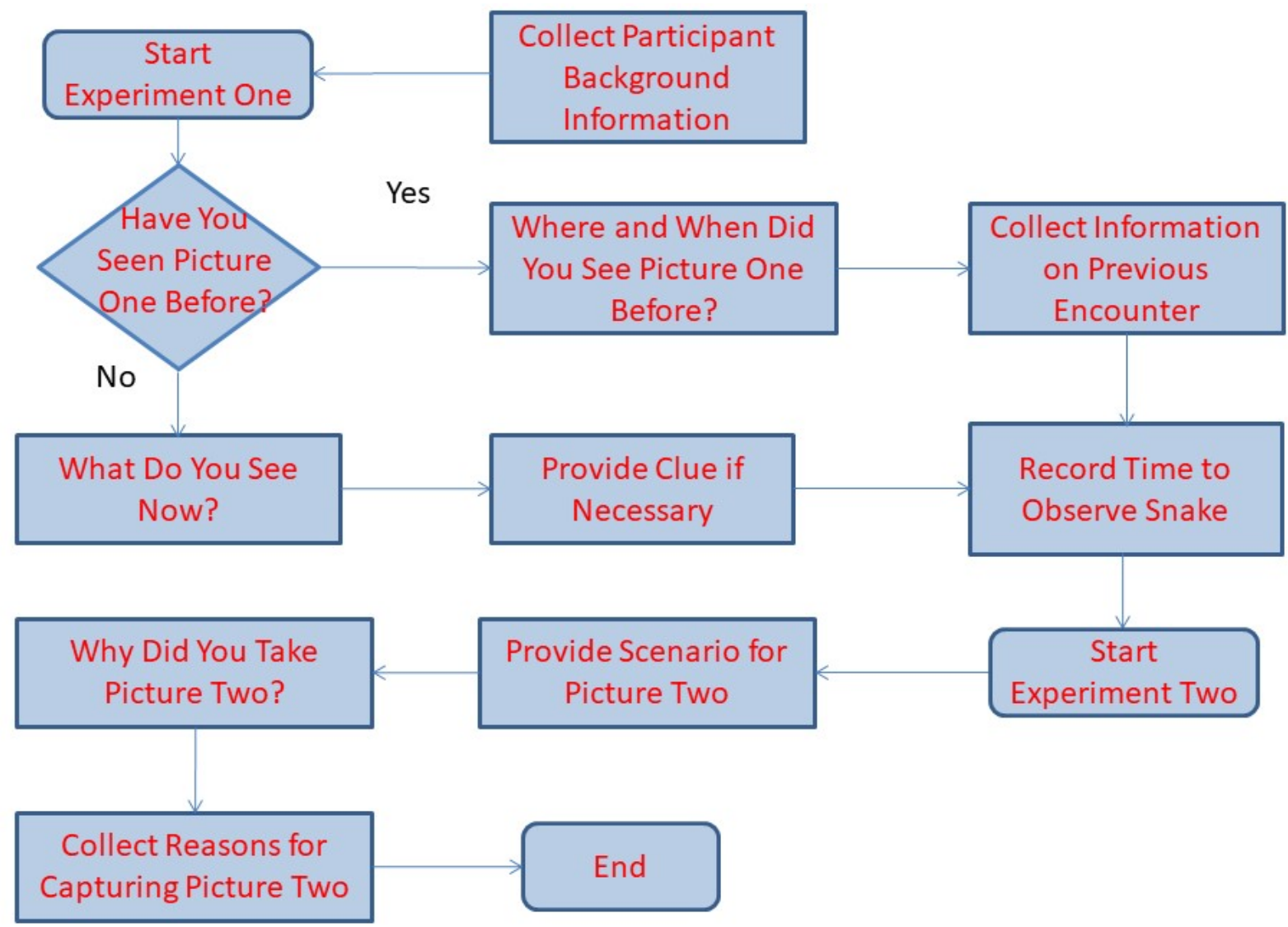

Figure 1: Flow Chart of Experiments 


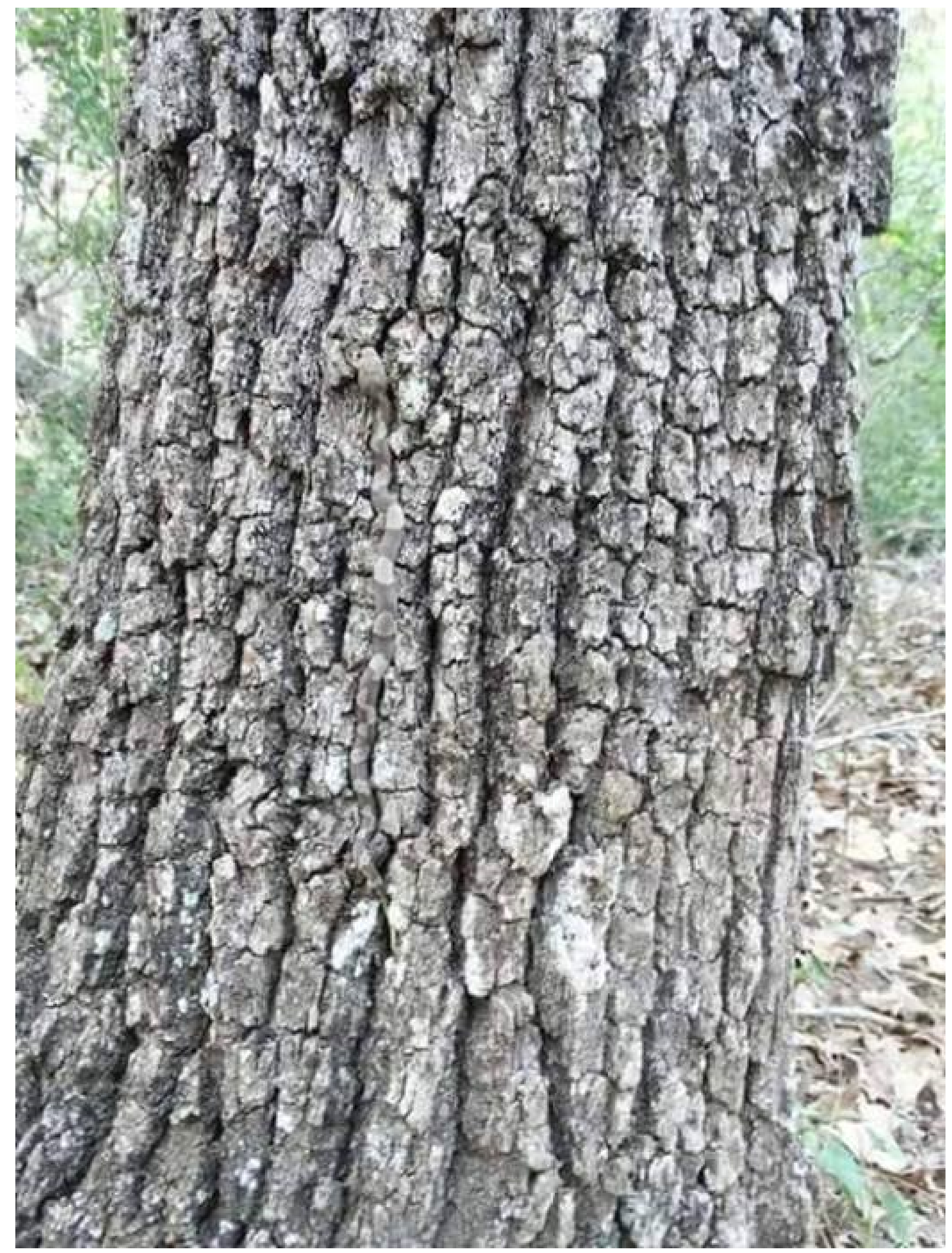

Figure 2: See and Sense The Snake 


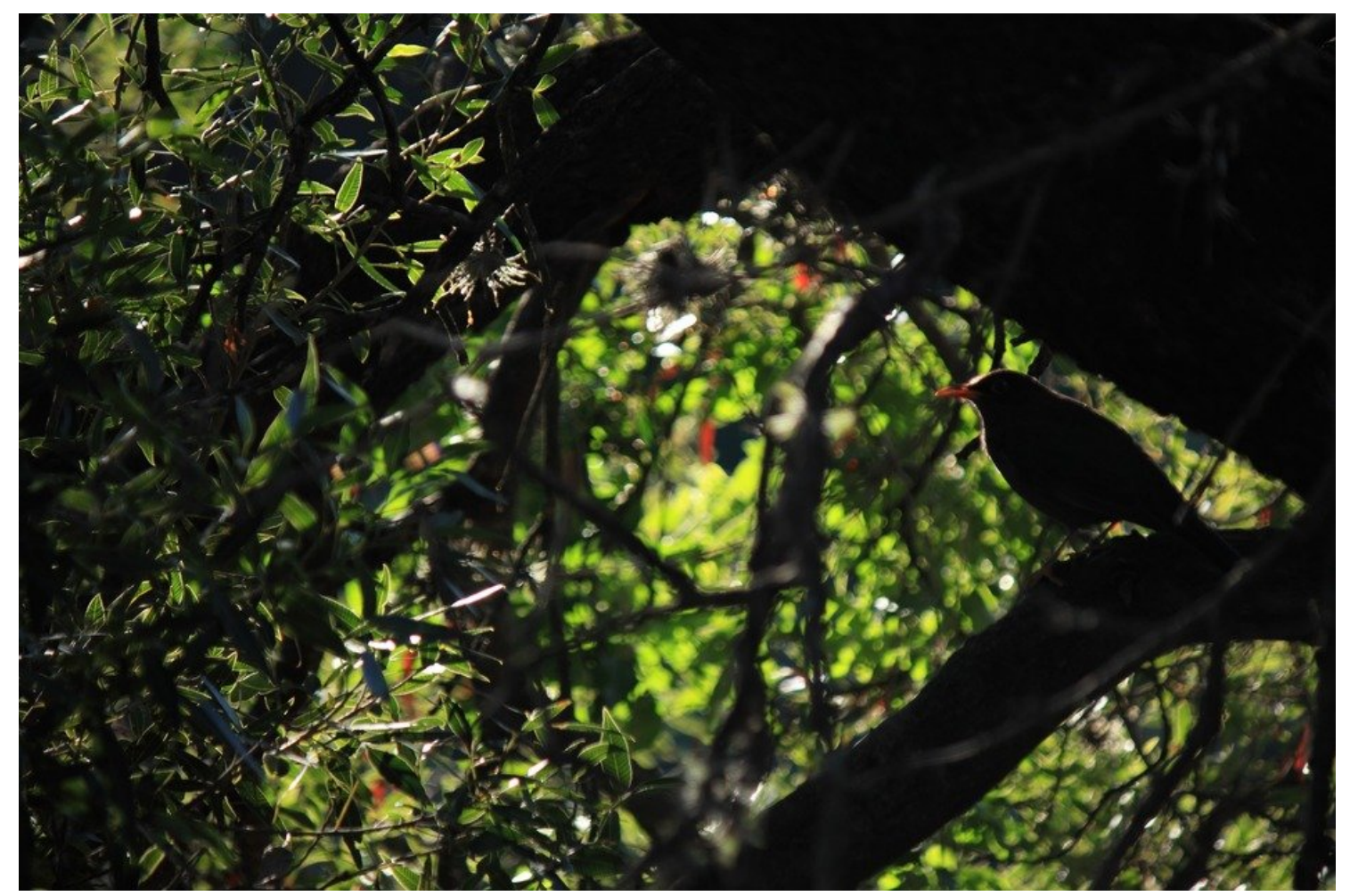

Figure 3: Wildlife Photographer

\begin{tabular}{|c|c|}
\hline $\log 12$ & $\theta \alpha @ \beta$ \\
\hline \hline $\log 200$ & $\alpha @ \theta$ \\
\hline $\log \frac{\mathbf{1 4}}{\mathbf{3}}$ & $\alpha \lambda \beta @ \delta$ \\
\hline $\log 0.3$ & $\beta \lambda \pi$ \\
\hline $\log 1.5$ & $\beta \lambda \alpha$ \\
\hline
\end{tabular}

(a) Somewhat Hard

\begin{tabular}{|c|c|}
\hline $\log 12$ & $2 x+y$ \\
\hline \hline $\log 200$ & $x+2$ \\
\hline $\log \frac{14}{3}$ & $x-y+z$ \\
\hline $\log 0.3$ & $y-1$ \\
\hline $\log 1.5$ & $y-x$ \\
\hline
\end{tabular}

(b) Relatively Easy

Figure 4: Match The Following: Two Examples 


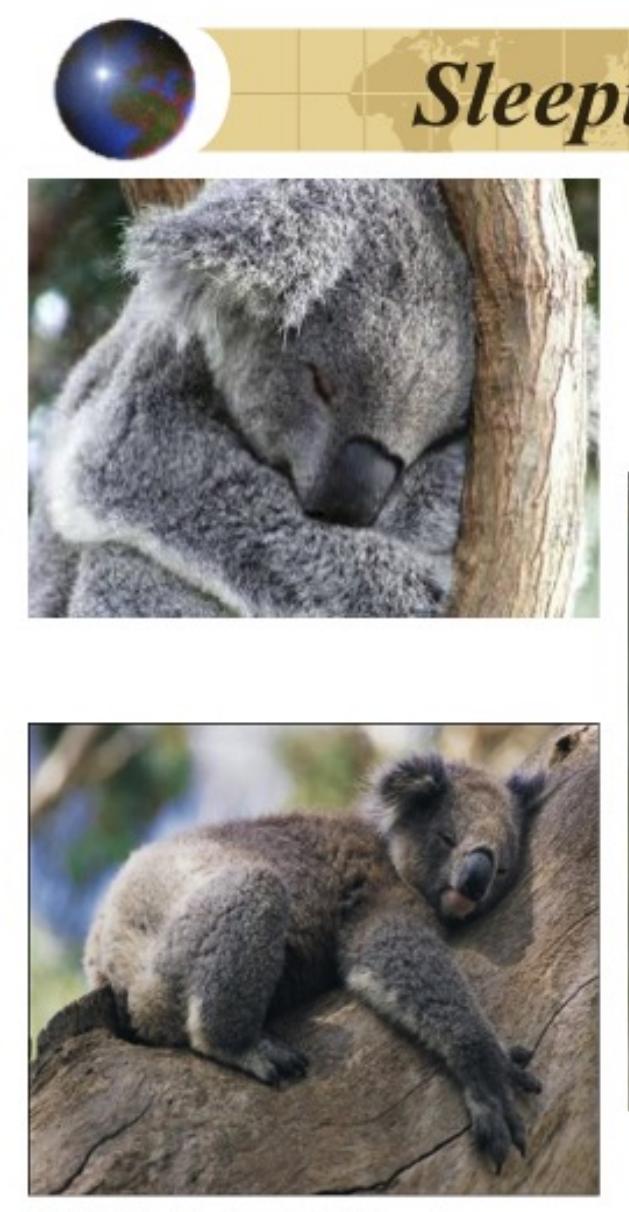

2016 Gain Knowledge Group. All Rights Reserved.

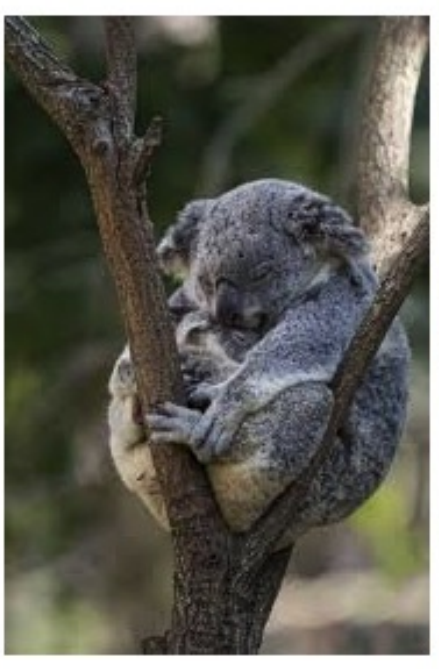

1
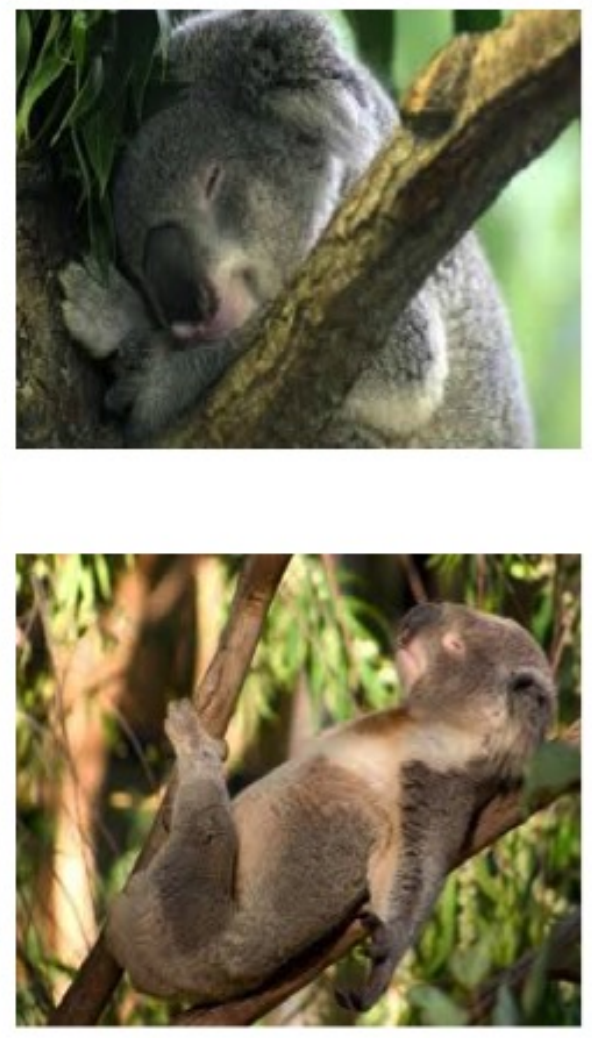

Figure 5: Sleeping Like A Koala 


\section{Recipe for a Remarkable Life (???)}

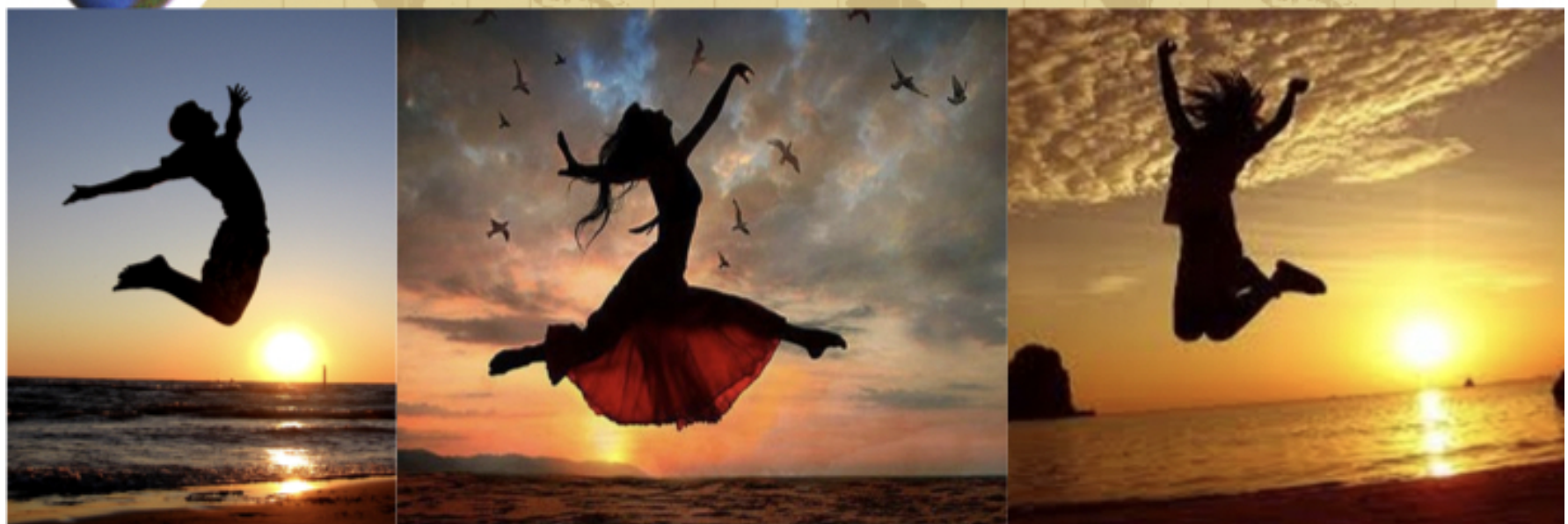

- Trust No One, but Love Everyone ...

- Travel Everywhere, and Respect Everytbing.

- Remember " $e$ ", the Exponential Function, Naturally Stands for Everyone, Everywhere and Everything (including Etbics, Evolution, Education and Examinations)...

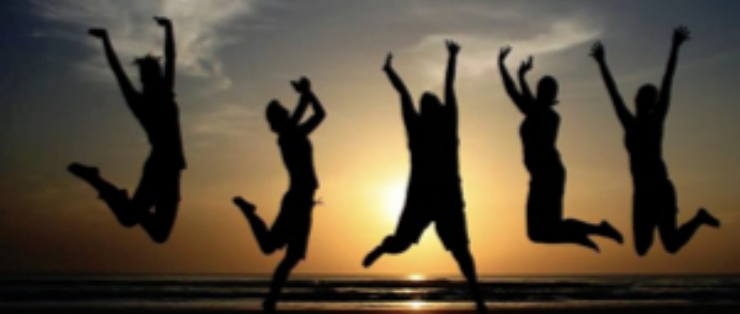

- As You Sense and Rejoice, Do your Best ...

- Relax !!! Someone Else will Take Care of the Rest...

๑2016 Gain Knowledge Group. Al Rights Reserved.

Figure 6: Recipe for a Remarkable Life 